\title{
Using Robots to Help People Habituate to Visible Disabilities
}

\author{
Laurel D. Riek and Peter Robinson \\ Computer Laboratory \\ University of Cambridge \\ Cambridge, UK CB30FD \\ Email: Laurel.Riek@cl.cam.ac.uk
}

\begin{abstract}
We explore a new way of using robots as humanhuman social facilitators: inter-ability communication. This refers to communication between people with disabilities and those without disabilities. We have interviewed people with head and facial movement disorders $(n=4)$, and, using a visionbased approach, recreated their movements on our 27 degreeof-freedom android robot. We then conducted an exploratory experiment $(n=26)$ to see if the robot might serve as a suitable tool to allow people to practice inter-ability interaction on a robot before doing it with a person. Our results suggest a robot may be useful in this manner. Furthermore, we have found a significant relationship between people who hold negative attitudes toward robots and negative attitudes toward people with disabilities.
\end{abstract}

\section{INTRODUCTION}

For many who work in the field of human-robot interaction, at some point they are inevitably faced with the problem of robot acceptance. This acceptance is explored from many perspectives, such as: finding common ground with a robot [1], how well a robot helps people accomplish their goals [2], how cultural differences [3], age differences [4], user expectations [5], robot appearance and behavior [6] factor in, and many others.

Sharkey and Sharkey [7] raise another compelling aspect of robot acceptance, which is their possible use as humanhuman interaction facilitators. They explore this idea within the context of elder care, and discuss ways in which robots have been used as interaction facilitators with other family members and peers [8], [9]. This idea also motivates many autism spectrum disorder interventions, where robots [10][14], embodied conversational agents [15], and other emotional prosthetic technologies [16] have been employed, their goal to aid transference of acquired social interaction skills from machines to other people.

This work has inspired us to explore a new aspect of humanhuman social facilitation by robots: inter-ability communication. This term refers to communication between people with disabilities (PWDs) and people without disabilities (PWODs). In the literature it's well documented that such encounters can be rife with difficulties for both parties [17], [18].

From the perspective of PWDs, they may experience both overt acts of stigmatizing behavior from PWODs, such as patronizing speech [19], inappropriate paternalism [20], violence [21], and social exclusion, as well as more subtle acts of stigmatization, such as hiring or job retetion discrimination
[22], aversive disabilism [20], early conversation termination or interaction avoidance [23], and other forms of non-verbal inhibition via proxemics, gestures, and gaze avoidance [24][26]. Furthermore, a large communicative burden is often placed upon the PWD, because they may have make extra effort to smooth the interaction, for example via the use of humor [27], [28] or disclosure [29].

For the PWOD, a lot of social pressure is often felt during an initial encounter with a PWD to "get it right" from a social interaction perspective. Social protocol dictates the suppression of certain emotions, such as pity, fear, repulsion, fascination, or surprise. Thus, PWODs often spend a lot of time monitoring their emotional displays, gaze, and language so as not to offend, which can create great strain on the interaction. They are often unsure how to act - if they should offer assistance (or not), whether or not they should discuss the disability, what their expectations should be, and which gestures and words to use or avoid [25], [30]. This can be particularly problematic for PWODs who have had less contact with people with disabilities [31], [32].

To help address these inter-ability communication gaps, many researchers have examined various kinds of disability awareness training programs, also termed "perceiver-director intervention strategies" [33]. The goal of such interventions is to engender positive attitudinal change among participants by attempting to induce a sense of empathy for people with disabilities. Initial efforts in this area include "experiential" learning, where able-bodied people simulate having a disability, or role-playing through the use of vignettes. As technology advanced some of this simulation was conducted via Virtual Reality [34], [35]. Other efforts were information-based, directly describing the challenges some PWDs face through the use of videos or lectures.

However, many of these methods have been criticized in the literature for not only being ineffective [36], but in some cases being counter-productive and inculcating the very negative attitudes they intended to combat [37]. By only focusing on the problems and difficulties faced by people with disabilities, their outgroup status is emphasized too strongly, making it difficult for PWODs to find common ground and further marginalizing PWDs. Alternatively, sometimes these training methods focus too much how a person overcame their disability, thus painting an unrealistic picture and creating 
the dangerous myth of the "supercrip" [38], [39]. French [37] argues that such exercises also fail to correctly simulate impairment, do not address the skills and strategies PWDs need in their daily lives to cope with their impairment, and do not adequately address "the cumulative social and psychological effect of encountering social and physical barriers over a lifetime." Furthermore, some groups serving PWDs have suggested that experiential learning is useless in the long term and does not lead to social transference; using a wheelchair for a day does not make one truly understand a daily wheelchair user's lifelong struggles [40], [41].

To date, the one perceiver-directed intervention that has been overwhelmingly effective for helping to cultivate positive attitudes and reduce communication uncertainty in inter-ability interaction is contact. Allport introduced the Contact Hypothesis in 1954 [42], which posits that stigmatization and prejudice toward particular groups stems from a lack of contact with such groups, giving people ample opportunity to form negative views. Allport suggested that by bringing people into contact with one another under certain conditions these attitudes could be changed. In 2006 Pettigrew and Tropp [43] published a meta-review of over 500 independent studies finding support for the Contact Hypothesis. The studies "involved a variety of... conditions, social groups, types of contact, and effect measures. The mean effect size obtained in this analysis $(\mathrm{d}=$ $-0.45, r=-0.21)$ certainly suggests that contact has the potential to reduce negative responses..." [33].

In some countries, however, inter-ability contact does not seem to happen naturally, and disability still remains invisible. For example, in the UK a recent study by the charity Scope found that $40 \%$ of Britons do not know anyone who is disabled, 90\% have never had a person with disabilities in their home for a social occasion, and $80 \%$ have never had a colleague at work who had a disability [44]. This is troubling given some recent figures cite people with disabilities comprise $18 \%$ of the British population [45].

Some organizations are proactively involved in disability equality training [46], which is a type of training inspired by Contact Theory. PWDs travel to businesses, schools, clinics, and other locations to provide training directly to PWODs. Such strategies have been shown to be successful in the literature [37], [47], but funding for such programs can be sparse, particularly within the current economic climate [48]. Thus, we are interested to know whether we might be able to augment existing programs and employ an interactive android robot capable of simulating a variety of disabilities, driven entirely on data collected from PWDs.

In our work with android robots, anecdotally we often find that some people express vehemently strong disgusted reactions when they encounter our robot for the first time, in their facial expressions, body gestures, and speech. While in other aspects of our research we wish to dampen this reaction, in this work we aim to capitalize on it. From our perspective, it is much more acceptable for people to be disgusted by our robot than to be disgusted by people with visible disabilities. Thus, by simulating motor impairments on our robot, we have attempted to give people the chance to practice inter-ability interaction before doing it for real.

By no means do we wish to replace existing programs that offer contact with people with disabilities, instead we simply wish to explore the use of an additional tool for implicitly raising awareness via the use of social facilitation. This paper describes a first attempt toward exploring this new use for robots, as inter-ability interaction facilitators.

\section{A. Research Questions}

We designed a between-subjects experiment in which participants pretended to be meeting someone for the first time. In Group 1, they watched a pre-recorded, 8-minute long video of a PWD (S2). In Group 2, they saw the same video, but the first four minutes were replaced by our android robot reenacting S2's movements. To simulate an actual conversation, participants were visually primed throughout the experiment with "ice-breaker" questions to ask.

During the experiment, participants' facial activity was recorded using electromyograms (EMG) in their corrugator supercilii (brow) and leavtor labii superioris (nostril/upper lip), two areas associated with the expression of disgust [49], [50]. We also collected a variety of behavioral measures to understand people's contact with and attitudes toward people with disabilities [51], [52], an interpersonal measure of disgust sensitivity [53], [54], and the Negative Attitudes Toward Robots (NARS) scale [55].

We are interested in the following research questions. First, do people habituate overall between the first part of the experiment and the second, as measured via EMG activity? We expect they would, simply due to getting bored as time went on, regardless of being in Group 1 or Group 2.

Second, is the robot as good as a person at causing people to habituate? If so, this would also lead us to feel confident in exploring the robot as a new method for social facilitation.

Third, might S2 be perceived as more likable if participants saw the robot first? And, might we see an overall relationship between contact with PWD and likeability?

Our fourth set of questions revolve around the behavioral measures we collected - are there correlations between contact with and attitudes toward PWDs, and disgust sensitivity, in line with what the literature would suggest?

Finally, we wonder if people who hold negative attitudes toward robots also have high disgust sensitivity. The literature suggests disgust sensitivity can predict attitudes toward outgroup members [56], so this measure may affect people's overall attitudes toward robots. We also wonder if negative attitudes toward PWDs is related to negative attitudes toward robots.

\section{DATA COLlection}

In our other work, we are collecting data of people with movement disorders and schizophrenia in order to drive realistic motion on our robot. The robot will later be used as a patient simulator in clinical contexts [57], [58]. 
To date, we have conducted face-to-face interviews with four people with head and neck movement disorders. Two people have cervical dystonia, which causes involuntary contractions of the neck and shoulder muscles. One person has generalized dystonia, which can cause similar types of involuntary muscle contractions, but are experienced throughout the body [59]. The fourth person has cerebral palsy, which is a disorder that can cause a variety of symptoms, though primarily ataxia, which makes muscle coordination difficult during coordinated movements, and spasticity, which causes tight or stiff muscles and exaggerated reflexes [60]. The two people with cervical dystonia had no speech impairments, but both the person with generalized dystonia and cerebral palsy did, and spoke with the aid of a Toby Lightwriter and a human interpreter respectively [57].

Participants were recruited via local support groups as well as a local trust (community) centre that serves people with disabilities in the East of England region. The recruitment notice described the general goals of the research, that participants would be video-taped during a face-to-face interview with the experimenter, and that they would be discussing common, every day subjects. It also noted participants would be remunerated with a $£ 10$ gift voucher to a local department store. Two of the interviews took place at the Computer Laboratory, and two took place at the local trust centre. All participants gave informed consent.

\section{A. Interview Content}

When selecting the content for the interview, we had several constraints. First, we did not want to create an asymmetrical relationship between the interviewer and interviewee, as this can create social inequality and can affect people's demeanor [61]. Second, we did not want the interviewee to feel compelled to self-disclose details about their disability. Finally, since for this work we were interested in first-time meetings, we wanted to ensure questions kept the conversations appropriately polite and formal [62].

After consulting the discourse, linguistics, and social pragmatics literature on first time meetings and rapport building (c.f., Sniad [63] and Spencer-Oatey [64], [65]), we generated a list of general, non-personal "ice breaker" type questions intended to build rapport, such as hobbies, food preferences, film and music tastes, etc. After speaking with the trust centre manager, we refined this list to be sensitive to the constraints of the people we were interviewing. For example, the person with generalized dystonia can only eat pureed food and thus would probably not like to discuss his food preferences; others in the local disability community may not like to discuss their place of residence because they are forced to move frequently, etc.

\section{B. Equipment Setup}

During the interview sessions, three cameras were trained on the interviewee. One camera directly faced the subject, and the other two were placed on the left and right about 2 meters away, at a 45 degree angle [57]. We also used a Tobii infrared

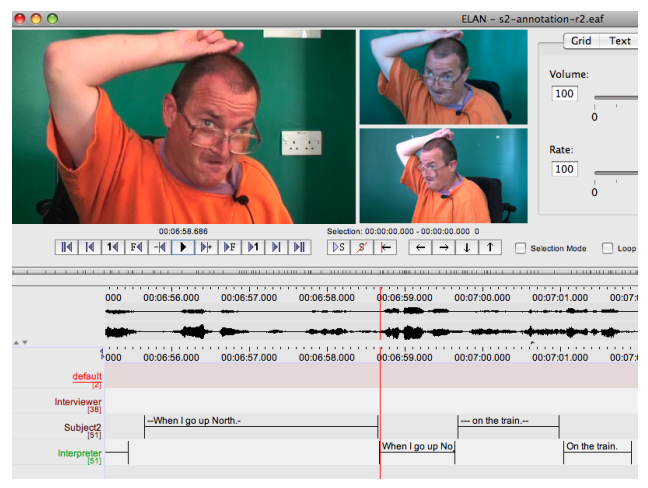

Fig. 1. A screenshot of the ELAN annotation tool [66], which we used to annotate the interview.

eye tracker to get precise pupil movements. The interviewer sat directly in front of the subject.

\section{MATERIALS}

\section{A. Stimuli Creation}

After careful consideration of both the interview content and how well our face tracker performed, we elected to use the interview with the person with cerebral palsy (S2).

We then used the ELAN annotation tool [66] to coarsely annotate the video. (See Figure 1). We annotated what S2 said, what his interpreter said, and what the interviewer said. This allowed us to understand the basic structure of the interview. In general we found it had the following structure: Greetings, Hobbies, Food Preferences, Computer Use, and Travel. With a few small edits this neatly divided the interview into two fourminute parts. Part I had a greeting, and then covered hobbies and food, and Part II covered computer use and travel.

The video was edited to remove all of the interviewer's speech, thus only containing the voices of S2 and his interpreter. There was also some background noise from the trust centre which we left in, in order to help make the stimuli feel more naturalistic.

We then had an eight-minute long video consisting of two parts. We used this to create two stimuli videos for our experiment. The first video, Video 1, consisted of the entire eight-minute long video of S2 (both Part I and Part II). The second video, Video 2, consisted of Part I depicting our robot "playing back" S2's head movements and facial expressions (4 minutes), followed by the original Part II video (4 minutes).

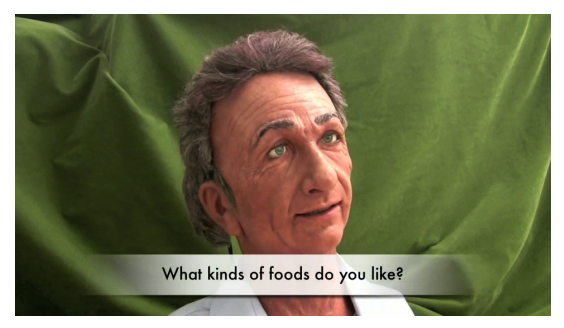

Fig. 2. A screenshot from the stimulus video, depicting an "ice-breaker" question the participant is primed to ask. 
The audio was identical in both videos. Furthermore, both videos had subtitles added to them at the same point, indicating which questions participants should ask when (See Figure 2). For example, in Part I, one of the questions was, "What kinds of foods do you like?". The questions also related to previous things S2 had mentioned. For example, at one point he said he enjoys beer, so the follow-up question is, "Which beer do you like the best?"

The number of questions in both parts were roughly equivalent, with seven questions in Part I and eight in Part II.

\section{B. Robot video stimulus creation}

To create motion for the robot, we ran Part I through our geometry-driven facial feature tracker (NevenVision) to extract 22 facial landmarks around the face. We also determined S2's "average" facial configuration, such as their mouth width, inner eye distance, etc. We then used these averages to generate action-unit (AU) based, frame-by-frame movements that can be used to drive our robot (See Baltrušaitis et al. [67] for more detail). Each AU maps nearly one-to-one to motors on our robot, Charles, a Hanson Robotics humanoid with 27 degrees of freedom (DOF) in total that correspond to the musculature of the human head [57]. (See Figure 3).

The robot has two microcontrollers: an SSC-32 to control the 20 Hitec HS- $82 \mathrm{mg}$ servos that move the brow, eyes, midface, and lips, and a Robotis Dynamixel Controller to control the 7 Dynamixel motors (RX-28, RX-64, and EX-106) in the mouth, jaw, head, and neck. A Java program controls communication with both microcontrollers and is resposible for ensuring they are synchronized. All movements on the robot are fully autonomous.

We filmed the robot re-enacting Part I. Due to limitations of one of our microcontrollers, Charles presently can move at approximately six frames/second (as opposed to the standard $30 \mathrm{fps}$ of the video). Thus, when creating the stimuli for the experiment, we accelerated the video to be five times faster, to correspond with the original Part I video and be four minutes long. We then added the original audio and priming subtitles, so it matched the original video precisely. The video was edited very slightly to ensure the robot's mouth movements corresponded with S2's speech.

In general the motion and facial expressions on the robot looked quite natural, and were very similar to the original video of S2. We have previously verified the validity of our mapping technique in an experimental setting, and found synthesized expressions on Charles are closely comparable to original video [67].

\section{Behavioral Measures}

We prepared five post-experimenal behavioral measures. The first was the Reysen Likeability measure [68], which is an 11-item instrument. An example question is, "I would ask this person for advice." We employed this measure because we were interested to know if S2 would be considered more likeable by participants who had seen the robot beforehand.

\begin{tabular}{ccc}
\hline & Part I & Part II \\
& Hobbies and Food & Computers and Travel \\
\hline Group 1 & Person (4 minutes) & Person (4 minutes) \\
Group 2 & Robot (4 minutes) & Person (4 minutes) \\
\hline \multicolumn{3}{c}{ TABLE I } \\
\multicolumn{4}{c}{ THE CONDITIONS USED IN THE EXPERIMENT. }
\end{tabular}

Also, it's another indirect measure of attitudes toward people with disabilities.

Our second measure was the Multidimensional Attitudes Scale Toward Persons With Disabilities (MAS) [51], [69]. This is a 24-item self-report measure that examines attitudes toward PWDs using a social scene vignette where "Pat" encounters a wheelchair user in a cafe. The participant must rate the way they think Pat might feel, think, or behave on three subscales: Affect (16 questions), Cognition (10 questions), and Behavior (8 questions). We selected this measure because it takes a multidimensional approach toward understanding attitudes PWOD have for PWDs, addresses soundness concerns found in other attitudes toward PWD scales [51], and avoids the trap of inadvertently inculcating negative attitudes [37].

The Contact toward Disabled Persons Scale (CDP) [52] was our third measure. This is a well-validated scale [32] inspired by Contact Theory [42], and has 20 items which measures how often a person encounters PWDs. An example item is, "How often have you worked with a physically disabled coworker?"

Our fourth measure was the Negative Attitudes Toward Robots Scale (NARS) [55]. This is a summed measure that assesses negative attitudes toward robots via a 5-point attitudinal scale. The measure contains three sub-scales: "negative attitudes toward emotions in interaction with robots," "negative attitudes toward the social influence of robots," and "negative attitudes toward situations of interaction with robots." [70]. We employed this measure because we were interested to know if there is a correlation between NARS scores and attitudes toward people with disabilities, as well as to disgust sensitivity.

Finally, the the Disgust Scale Revised (DS-R) was our fifth measure [53], [54]. This is a 25-item, well-validated instrument [54] measuring attitudes toward disgusting stimuli. For example, "You see a man with his intestines exposed after an accident." In the literature this measure found to be strongly correlated with negative attitudes toward outgroup members [56], as well as EMG activity in the corrugator supercilii (brow) and leavtor labii superioris (nostril/upper lip) muscles [49], [50].

\section{Methodology}

We conducted a between-subjects, video-based experiment in the laboratory. Participants were randomly assigned to see either Video 1 or Video 2. In all other respects, the two conditions were identical.

\section{A. Participants}

Participants were recruited via Gumtree, University electronic bulletin board, and word of mouth. The recruitment 


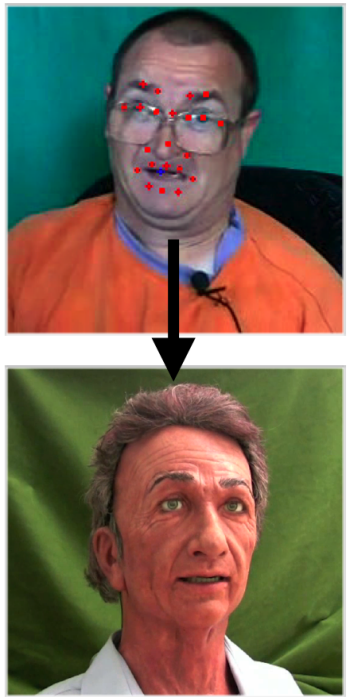

Fig. 3. 22 facial feature points from the original video are directly mapped onto motors on the robot, to create naturalistic movement.

notice indicated that we were studying how people talk to each other during first time meetings. It also indicated participants would have their "brain activity" measured during the experiment by having electrodes placed on their head, and that they would be paid a $£ 5$ gift voucher for their participation. All participants gave informed consent, and were thoroughly debriefed at the end of the experiment.

26 people participated in our experiment in total, 13 female and 13 male. Participants' ages ranged from 18 - 65 with the average age 31.9 , (s.d. $=12.23$ ). With regards to nationality, our sample was quite diverse - three participants were German, two were Indian, one was Mexican, one was Nigerian, two were Polish, one was Romanian, one was Russian, two were Singaporean, three were American, and ten were British. All were fluent in English. Of the non-British participants, four have lived in the UK less than one year, seven have lived here for one to three years, two have lived here for five to seven years, one has lived here 10 or more years, and two did not live in the UK.

In terms of occupation, only about half of all participants were employed by or students at the University, others lived in or were just passing through Cambridge. Six participants were undergraduate students, six were graduate students, three were postdocs, two were accountants, four were administrative assistants, and five were unemployed.

Three participants reported having a disability and elected to describe them. All were physical disabilities, but only one was visible, and that person was a wheelchair user.

\section{B. Procedure}

After reading instructions about the experiment, having a chance to ask questions, and giving informed consent, participants were seated at the computer and fitted with electrodes. The electrode placement is described in Section
IV-C. The EMG and video camera recording was started, and the experimenter left the room.

In the first part of the experiment, participants were told that they would see two short videos depicting a subject having a conversation. Participants were told to pretend to be meeting this person for the first time, and that they would be asking getting-to-know you questions aloud. These questions were displayed as subtitles on the video as prompts.

After completing the mock conversation, participants answered the Reysen likeability measure, and were instructed to base their answers on the video they had just seen (i.e., the video featuring the person with a disability). Then, participants were instructed to call the experimenter back into the room.

The experimenter re-entered the room and removed the electrodes, turned off the EMG device, and turned off the video camera. The experimenter again left the room.

Participants then completed the MAS, CDP, NARS, and DS$\mathrm{R}$ measures, and answered some demographic questions. They also read a debriefing form about the experiment. This took about 10-15 minutes. The experimenter then re-entered the room, offered to answer any questions, and paid participants for their participation.

\section{EMG Measurement}

In the literature on disgust, it is well understood that activity in the corrugator supercilii (brow) and leavtor labii superioris (nostril/upper lip) are strongly correlated with disgust [49], [50]. Activity in these muscles correlates strongly both with disgusting stimuli and self-report disgust measures.

For this work, we were interested in overall facial muscle activity in these regions. We thus attached electrodes to these areas using placements suggested by Fridlund and Cacioppo [71]. We prepared the electrode contact sites with alcohol, and attached silver choride Tyco ARBO disposable electrodes on the left side of the face.

The data were received by a NeXus-4 four channel 24 bit ADC device and transmitted over bluetooth to a Windows 7 PC. The PC ran a C\# program that received the raw data and outputted it out to a text file. Data was sampled at $1024 \mathrm{hz}$.

Offline, we examined the data in concert with video recordings, to note the precise start and stop times of the videos. We were thus able to remove approximately $35000 \mathrm{~ms}$ of data from the start of the recording (since participants were orienting by reading instructions on the screen). This ensured we could remove muscle artifacts from the data (c.f. Winkielman and Cacioppo [72]). We then applied a Butterworth bandpass filter to the data at $20 \mathrm{hz}$, to help account for long term drift. To get rid of noise, we squared the data, and then calculated a running mean, as sampled every $1500 \mathrm{~ms}$. We then removed outliers two standard deviations away from the mean. Then, we took the integral of the data to arrive at an overall facial muscle activity score. Finally, these scores were scaled by the number of questions per their respective Part. 


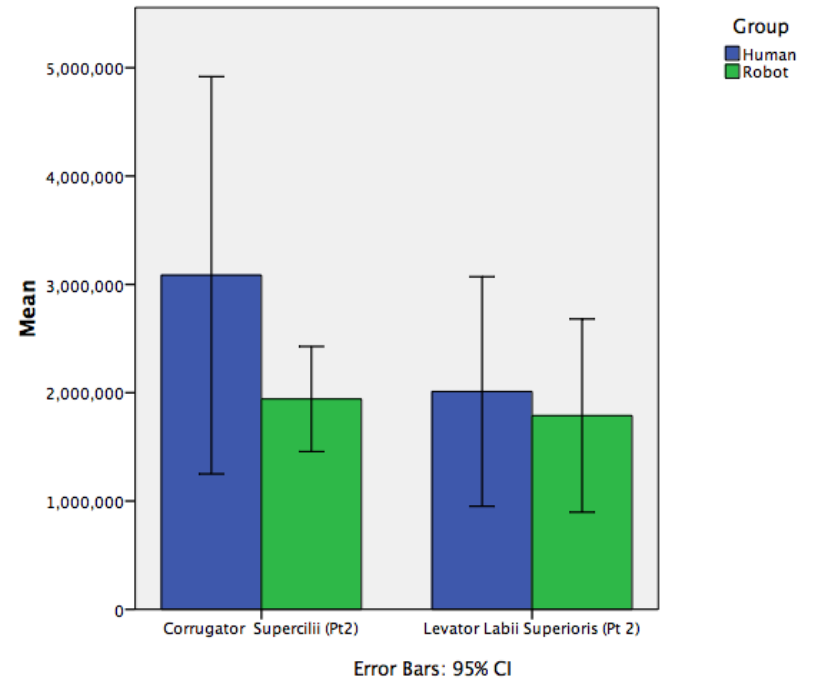

Fig. 4. The overall facial muscle activity in Part II of the experiment, per condition and per group.

\section{RESULTS}

\section{A. Measures}

Our dependent variable was disgust habituation, as measured via the amount of facial muscle activity in the corrugator supercilii (brow) and leavtor labii superioris (nostril/upper lip). Our independent variable was treatment group, Group 1 saw just S2 in both parts, and Group 2 saw robot "playback" of S2 in Part I followed by just S2 in Part II. (See Table I).

We also collected five behavioral measures: Reysen Likeability, Multidimensional Attitudes Scale Toward Persons With Disabilities (MAS), Contact with Disabled Persons Scale (CDP), Negative Attitudes Toward Robots Scale (NARS), and the Disgust Scale Revised (DS-R), which each produce a summed-measure score.

For the EMG data analysis, four subjects were excluded due to sensor malfunction.

\section{B. Overall habituation}

We first checked to see if there was more facial muscle activity between Part 1 and Part 2, per group. To do this, we performed a mixed ANOVA, with Part (1 or 2) and Muscle (corrugator supercilii or leavtor labii superioris) as our within-subjects variables, and Group (Robot or Human) as our between-subjects factor. This test revealed a significant overall difference difference between Part 1 and Part 2, F(1,20) $=4.875, p<.05, r=.44$, indicating a medium effect. (Bonferonni corrected). There were no significant main or interaction effects between any of the other variables. Thus, people habituated between Part 1 and Part 2, as we expected.

\section{Part II facial muscle activity}

Next, we wanted to know if seeing a robot in Part I was no worse than seeing a person in Part I with regards to Part II facial activity scores. In the biostatistics literature this is referred to as a non-inferiority test. Generally in a superiority trial, the null hypothesis is that both treatments are equal, and the alternative hypothesis is that they are different. In this paradigm, a Type I error would be "falsely finding a treatment effect when there is none" and a Type II error is "failing to detect a treatment effect when truly one exists." However, for a noninferiority trial the alternative and null hypotheses are reversed. One commits a type I error by "the erroneous acceptance of an inferior new treatment", and a type II error by the erroneous rejection of a truly noninferior treatment" [73].

Looking at the confidence intervals (see Fig. 4), one can see that for the corrugator supercilii muscle, the robot group does no worse than the human group, as the top bound of the 95\% confidence interval for the robot condition is lower than the mean of the human condition [73]. For the leavtor labii superioris muscle, there is substantial overlap between the two conditions, which may be due to the fact that participants were talking during the experiment.

Thus, we can confidently state for one primary measure of disgust, the corrugator supercilii, we can accept the alternative hypothesis and state that the robot is no worse than a human in terms of inducing habituation. But for the leavtor labii superioris, we can make no superior or inferior claims about the two conditions from this sample, but we can state that they do have substantial overlap.

\section{Likeability}

As the literature suggests, we found a correlation between CDP scores and likeability scores, $r_{s}=.39, p<.05$. Thus, more contact with PWDs leads to higher likeability of PWDs. This further supports the Contact Theory hypothesis.

We also were interested to see if participants in Group 2 viewed S2 as more likeable than participants in Group 1 (i.e., did the robot affect likeability scores). There was no significant differences between these groups, $t(24)=.43, p>.05$

\section{E. Attitudes toward PWDs}

The MAS Cognition subscale negatively correlated both with likeability scores, $r=-.42, p<.05$, and CDP scores, $r=$ $-.60, p<.01$. This suggests people who hold think negatively about PWDs are less likely to like them, and also less likely to have had much contact with them.

The MAS Cognition subscale was also significantly correlated with DS-R, $r=.45, p<.05$. This indicates people who are more sensitive to disgust are more likely to think negatively about PWDs.

\section{F. Negative attitudes toward robots}

In general we predicted someone with a higher disgust sensitivity score would also hold negative attitudes toward robots (as one might expect as people with higher DS-R scores tend to hold negative attitudes toward other outgroup members [56]). Removing two outliers that were more than two standard deviations from the mean on the DS-R, we find some support for this idea, $r=.34, p$ (one-tailed) $=.05$.

We also found a significant relationship between NARS scores and the MAS Affect subscale, $r=.45, p<.05$. 
This suggests that people who have negative feelings when encountering people with disabilities are likely to also have negative attitudes toward robots.

\section{DISCUSSION}

The results from our exploratory experiment suggest that an interactive robot driven by natural data may be able to serve as a human-human social interaction facilitator for inter-ability communication. For this sample, it appears a robot is no worse than a human at causing causing people to habituate to visible disability on the dimension of expressed disgust, which may help reduce uncertainty in inter-ability interaction [42].

We found strong support for Allport's Contact Theory [42] across several measures, including Likeability and CDP, MAS Cognition and CDP, and MAS Cognition and DS-R. This suggests contact with PWDs will help inculcate positive attitudes.

We also found a significant relationship between NARS and MAS Affect, which suggests robots may in fact be viewed as another sort of "out-group", like people with disabilities, inspiring discomfort and uncertainty [25], [30]. Further work is needed to understand what this relationship might mean.

This experiment has a few limitations. First, in order to precisely control the stimuli and EMG timings, our experiment was video-based, and contained artificial dialogue. Ultimately we would like to conduct live trials (with robots, participants, and PWDs), but in this work we were taking just a first step toward exploring this research area.

Another limitation is that facial expression of disgust is only one variable of many that may play into inter-ability communication. In the future we would like to explore other implicit measures of inhibiting behavior during interaction, such as eye gaze, gesture reduction, and proxemics [24]-[26]. Certainly work in human-robot interaction suggests people may alter their interaction on these dimensions when encountering a robot as opposed a person; it would be interesting to examine this in light of inter-ability communication facilitated by robots.

\section{CONCLUSION}

We see interactive robots that can simulate disability as being potentially useful in several domains. First, it may be possible to use robots as an additional item in the disability equality trainer's toolkit. In addition to already being able to discuss their own disability, they may also be able to allow trainees to experience interacting with a variety of people with other types disabilities via the robot. The robot provides a layer of anonymity for other PWDs who may be happy to give data to animate the robot but do not want to personally engage in equality training themselves.

Presently we are examining the use of robots as simulated patients in clinical training contexts [57], [58]. The work described in this paper suggests that we are able to replicate head and neck movement disorders in a plausible way, in fact, one participant remarked, "I didn't realize that the person in the first part was a robot!"
We will soon be exploring simulating other disorders on the robot, such as autism and schizophrenia. Encouraged by the work of Battersby et al. [74], we wonder if we might be able to use the robot as a new way of modeling and understanding these disorders by creating physical, interactive models. Such a use of robots could be a new and exciting research area, and we look forward to exploring it.

\section{ACKNOWLEDGMENTS}

This work is supported by the Qualcomm Studentship in Computing. We'd also like to thank Tadas Baltrušaitis, Andreas Bulling, Peter Cannon, Per Ola Kristensson, Ian Davies, Judith Holler, Simone Schnall, the NHS Papworth Trust, and the UK Dystonia Society.

\section{REFERENCES}

[1] K. Stubbs, D. Wettergreen, and I. Nourbakhsh, "Using a robot proxy to create common ground in exploration tasks," in Proc. of the 3rd ACM/IEEE International Conference on Human-Robot Interaction, 2008.

[2] A. Weiss, D. Wurhofer, M. Lankes, and M. Tscheligi, "Autonomous vs. tele-operated: how people perceive human-robot collaboration with HRP-2," in Proc. of the 4th ACM/IEEE International Conference on Human-Robot Interaction, 2009.

[3] L. Wang, P. Rau, V. Evers, B. Robinson, and P. Hinds, "When in Rome: the role of culture \& context in adherence to robot recommendations," in Proc. of the 5th ACM/IEEE International Conf. on Human-Robot Interaction, 2010.

[4] M. Heerink, B. Krose, V. Evers, and B. Wielinga, "The influence of a robot's social abilities on acceptance by elderly users," in The 15th IEEE Int'l Symposium on Robot and Human Interactive Communication (RO-MAN), 2006.

[5] K. Tsui, M. Desai, and H. Yanco, "Considering the bystander's perspective for indirect human-robot interaction," in Proc. of the 5th ACM/IEEE Int'l Conference on Human-Robot Interaction, 2010.

[6] J. Goetz, S. Kiesler, and A. Powers, "Matching robot appearance and behavior to tasks to improve human-robot cooperation," RO-MAN, 2003.

[7] A. Sharkey and N. Sharkey, "Ethical issues in robot care for the elderly: Dystopia or optimism," in In Proc. of The Second Int'l Symposium on New Frontiers in Human-Robot Interaction at AISB 2010, 2010.

[8] M. Kanamori, M. Suzuki, and M. Tanaka, "Maintenance and improvement of quality of life among elderly patients using a pet-type robot," Jpn J Geriatr, vol. 39, no. 2, 2002.

[9] K. Wada and T. Shibata, "Robot therapy in a care house-its sociopsychological and physiological effects on the residents," in Proc. of the 2006 IEEE Int'l Conference on Robotics and Automation, 2006.

[10] K. Dautenhahn and I. Werry, "Towards interactive robots in autism therapy: background, motivation and challenges," Pragmatics \& Cognition, vol. 12, no. 1, 2004.

[11] D. Feil-Seifer and M. Matarić, "Toward socially assistive robotics for augmenting interventions for children with autism spectrum disorders," in Experimental Robotics, 2009.

[12] H. Kozima, M. Michalowski, and C. Nakagawa, "A playful robot for research, therapy, and entertainment," Int J Soc Robot, vol. 1, 2009.

[13] B. Robins and K. Dautenhahn, "Encouraging social interaction skills in children with autism playing with robots," Enfance, vol. 59, no. 1, 2007.

[14] B. Scassellati, "How social robots will help us to diagnose, treat, and understand autism," Robotics Research, 2007.

[15] A. Tartaro and J. Cassell, "Playing with virtual peers: bootstrapping contingent discourse in children with autism," in Proc of the 8th Int'l Conference for the Learning Sciences (ICLS '08), 2008.

[16] R. el Kaliouby and P. Robinson, "Therapeutic versus prosthetic assistive technologies: the case of autism," Assistive Technology, 2007.

[17] D. Braithwaite and T. Thompson, Handbook of communication and people with disabilities: Research and application. Lawrence Erlbaum, 2000.

[18] M. Hebl and R. Kleck, "The social consequences of physical disability," The social psychology of stigma, 2000. 
[19] S. A. Fox and H. Giles, "Interability Communication," Journal of Language and Social Psychology, vol. 15, no. 3, 1996.

[20] M. Deal, "Aversive disablism: subtle prejudice toward disabled people," Disability \& Society, vol. 22, no. 1, 2007.

[21] R. Ramesh, "EHRC to launch inquiry into disability hate crimes," The Guardian, Jun. 2010

[22] P. Miller, S. Gillinson, and J. Huber, "Disablist Britain: Barriers to independent living for disabled people in 2006," London.

[23] C. Fichten, "Students with physical disabilities in higher education: Attitudes and beliefs that affect integration," Attitudes toward persons with disabilities, 1988.

[24] E. Goffman, Stigma: Notes on the management of spoiled identity. Touchstone, 1986.

[25] T. Grove, "Conversations With Able-Bodied and Visibly Disabled Strangers An Adversarial Test of Predicted Outcome Value and Uncertainty Reduction Theories," Human Commun Res, vol. 17, no. 4, 1991.

[26] R. Kleck, "Physical stigma and nonverbal cues emitted in face-to-face interaction," Human Relations, vol. 21, no. 1, 1968.

[27] D. K. Pinch, "Spontaneous Irony in Post-stroke Individuals," PhD, University of Victoria, 1995.

[28] K. Shultz and D. Germeroth, "Should We Laugh or Should We Cry? John Callahan's Humor as a Tool to Change Societal Attitudes Toward Disability," Howard Journal Of Communications, vol. 9, no. 3, 1998.

[29] F. Belcrave and J. Mills, "Effect upon desire for social interaction with a physically disabled person of mentioning the disability in different contexts," Journal of Applied Social Psychology, vol. 11, no. 1, 1981.

[30] R. Thomson, Extraordinary bodies: Figuring physical disability in American culture and literature. Columbia Univ Press, 1997.

[31] J. Park, J. Faulkner, and M. Schaller, "Evolved disease-avoidance processes and contemporary anti-social behavior: Prejudicial attitudes and avoidance of people with physical disabilities," J Nonverbal Behav, vol. 27, no. 2, 2003.

[32] S. R. Pruett, E.-J. Lee, F. Chan, and F. J. Lane, "Dimensionality of the Contact With Disabled Persons Scale: Results From Exploratory and Confirmatory Factor Analyses," Rahabil Couns Bull, vol. 51, no. 4, 2008.

[33] A. Dijker and W. Koomen, Stigmatization, tolerance and repair: an integrative psychological analysis of responses to deviance. Cambridge University Press, 2007.

[34] J. e. a. Banks, "Constructing the hallucinations of psychosis in virtual reality," J Netw Comput Appl, vol. 27, no. 1, 2004.

[35] J. McComas and H. Sveistrup, "Virtual Reality Applications for Prevention, Disability Awareness, and Physical Therapy Rehabilitation in Neurology: Our Recent Work," Journal of Neurologic Physical Therapy, vol. 26, no. 2, 2002.

[36] C. Banks, "Creating Positive Attitudes toward People with Disabilities through Inclusion," Ph.D. dissertation, Hanover College, 2008.

[37] S. French, "Simulation Exercises in Disability Awareness Training: A Critique," Disability \& Society, vol. 7, no. 3, 1992.

[38] M. Hardin and B. Hardin, "The "supercrip" in sport media: Wheelchair athletes discuss hegemony's disabled hero," Sociology of Sport Online, vol. 7, no. 1, 2004

[39] J. Smart, Disability, society, and the individual. Aspen, 2001.

[40] FWD, "Why don't non-disabled people trust people with disabilities anyway?" Feminists with Disabilities, 2010.

[41] S. Playforth, "Training in disability awareness and equality," 2005.

[42] G. Allport, The nature of prejudice. Basic Books, 1979.

[43] T. Pettigrew and L. Tropp, "A meta-analytic test of intergroup contact theory," J Pers and Soc Psychol, vol. 90, no. 5, 2006.

[44] Scope, "Disabled people invisible in Britain today," 2010. [Online]. Available: http://www.scope.org.uk/news/comres-poll

[45] EFD, "Employer's forum on disability: Disability in the UK," 2010.

[46] K. Gillespie-Sells and J. Campbell, "Disability Equality Training," London: Central Council for the Ed. and Training of Social Work, 1991.

[47] B. Krahé and C. Altwasser, "Changing negative attitudes towards persons with physical disabilities: an experimental intervention," Journal of Community \& Applied Social Psychology, vol. 16, no. 1, Jan. 2006.

[48] J. Pring, "Minister warned chancellor of spending cuts equality duty," Disability News Service, Aug. 2010.

[49] P. J. de Jong, M. Peters, and I. Vanderhallen, "Disgust and disgust sensitivity in spider phobia: Facial emg in response to spider and oral disgust imagery," Journal of Anxiety Disorders, vol. 16, no. 5, 2002.
[50] A. R. Yartz and L. W. Hawk, "Addressing the specificity of affective startle modulation: fear versus disgust," Biological Psychology, vol. 59, no. 1,2002

[51] L. Findler, N. Vilchinsky, and S. Werner, "The Multidimensional Attitudes Scale Toward Persons With Disabilities (MAS): Construction and Validation," Rahabil Couns Bull, vol. 50, no. 3, 2007.

[52] H. E. Yuker and M. K. Hurley, "Contact with and attitudes toward persons with disabilities: The measurement of intergroup contact." Rehabilitation Psychology, vol. 32, no. 3, 1987.

[53] J. Haidt, C. McCauley, and P. Rozin, "Individual differences in sensitivity to disgust: A scale sampling seven domains of disgust elicitors," Pers Indiv Differ, vol. 16, no. 5, 1994.

[54] B. Olatunji, N. Williams, D. Tolin, C. Sawchuk, L. Elwood, J. Lohr, and J. Abramowitz, "The Disgust Scale: Item analysis, factor structure, and suggestions for refinement." Psychol Assess, vol. 19, no. 3, 2007.

[55] T. Nomura, T. Suzuki, T. Kanda, and K. Kato, "Measurement of negative attitudes toward robots," Interaction Studies, vol. 7, 2006.

[56] G. Hodson and K. Costello, "Interpersonal disgust, ideological orientations, and dehumanization as predictors of intergroup attitudes," Psychological Science, vol. 18, no. 8, 2007.

[57] L. D. Riek and P. Robinson, "Synthesizing head and facial movement disorders on android robots," in In Proc. of the ACM / SSPNET 2nd Int'l Symposium on Facial Analysis and Animation, Oct 2010.

[58] - "Teaching clinical communication with expressive robots." in Handling Gesture: Theory and Method in Gesture Studies. Int'1 Society for Gesture Studies (ISGS), July 2010.

[59] DMRF, "Dystonia Medical Research Foundation: Forms of dystonia," 2010, last accessed $10 \mathrm{Sep}$ 2010. [Online]. Available: http://www. dystonia-foundation.org/pages/forms_of_dystonia/41.php

[60] NINDS, "National Institute of Neurological Disorders and Stroke: Cerebral palsy," 2010. [Online]. Available: http://www.ninds.nih.gov/ disorders/cerebral_palsy/cerebral_palsy.htm

[61] E. Goffman and J. Best, Interaction ritual: Essays in face-to-face behavior. Aldine De Gruyter, 2005.

[62] C. A. Ferguson, "The structure and use of politeness formulas," Language in Society, vol. 5, no. 2, 1976.

[63] T. Sniad, "It's not necessarily the words you say, it's your presentation': Teaching the interactional text of the job interview," Journal of Pragmatics, vol. 39, no. 11, 2007.

[64] H. Spencer-Oatey, "Managing rapport in talk: Using rapport sensitive incidents to explore the motivational concerns underlying the management of relations," Journal of Pragmatics, vol. 34, no. 5, 2002.

[65] H. Spencer-Oatey and J. Xing, "Managing Rapport in Intercultural Business Interactions: a comparison of two Chinese-British welcome meetings," Journal of Intercult Stud, vol. 24, no. 1, 2003.

[66] H. Brugman and A. Russel, "Annotating multimedia/multi-modal resources with ELAN," in Proc. of the 4th Int'l Conference on Language Resources and Evaluation (LREC '04), 2004.

[67] T. Baltrušaitis, L. D. Riek, and P. Robinson, "Synthesizing expressions using facial feature point tracking: How emotion is conveyed," in Proc. of the ACM Multimedia Workshop on Affective Interaction in Natural Environments (AFFINE), 2010.

[68] S. Reysen, "Construction of a new scale: the Reysen Likability scale," Social Behavior and Personality: an int'l journal, vol. 33, no. 2, 2005.

[69] N. Vilchinsky, S. Werner, and L. Findler, "Gender and Attitudes Toward People Using Wheelchairs: A Multidimensional Perspective," Rahabil Couns Bull, vol. 53, no. 3, 2010.

[70] L. Riek, T. Rabinowitch, P. Bremner, A. Pipe, M. Fraser, and P. Robinson, "Cooperative gestures: effective signaling for humanoid robots," in Proc. of the 5th ACM/IEEE Int'l Conference on Human-Robot Interaction, 2010.

[71] A. Fridlund and J. Cacioppo, "Guidelines for Human Electromyographic Research," Psychophysiology, vol. 23, no. 5, 1986.

[72] P. Winkielman and J. Cacioppo, "Mind at ease puts a smile on the face: psychophysiological evidence that processing facilitation elicits positive affect." J Pers and Soc Psychol, vol. 81, no. 6, 2001.

[73] G. Piaggio, D. Elbourne, D. Altman, S. Pocock, and S. Evans, "Reporting of noninferiority and equivalence randomized trials: an extension of the CONSORT statement," Journal of the American Medical Association, vol. 295 , no. 10 , p. 1152,2006

[74] S. A. Battersby, M. Lavelle, P. G. Healey, and R. McCabe, "Analysing interaction: A comparison of $2 \mathrm{~d}$ and $3 \mathrm{~d}$ techniques," in Workshop on Multimodal Corpora, 2008. 